\title{
E- Resource for Technical Institute \& Engineering Colleges a Boon to libraries \& information Centers in India
}

\author{
Mr. Vijay Pandurang Satao. \\ Siddhivinayak Technical Campus, Khamgaon,(MS) India
}

\begin{abstract}
Today availability of e- resources in a college library is very common. But their proper and maximum use is a matter for discussion. The present paper examines the existence of various e-resource databases in Siddhivinayak technical campus college library. The study also highlights the preferences and importance of online resources among the teacher and students.
\end{abstract}

\section{Introduction}

Advances in computer applications during the past few decades have brought radical changes in the way information is gathered, store, organized, accessed, retrieved and consumed. the application of computers in information processing has brought several product and services modes of scholarly communication; their potential for delivering goods is quite vast, as they overcome successfully the geographical limitations associated with the print media. Further, the distribution time between product publication and its delivery has been drastically reduced. The Internet can be used for efficient retrieval and meeting information needs . This work. This important fact is convincing many libraries to move towards digital e- resources, which are found to be less expensive and more useful for access. This is especially helpful to distant learners who have limited time to access the libraries from outside by dial up access to commonly available electronic resources, mainly CDROM, OPACs and internet, which are replacing the print media.

Libraries have witnessed a great metamorphosis in recent years both in their collection development and in their service structure.

\section{Objectives:-}

The main objective of this study is to analyze dependency of the teachers and engineering college's student on e- resources, the perceived impact of the e- resources on their academic efficiency and problems faced by them while using the e- resources. This survey was particularly conducted to assess the benefits of the e- resources over conventional sources of information.

Some of the major objectives are to;

- Know the different type of electronic resources and services available in the Siddhivinayak Technical Campus library;

- Study the different type of electronic resources used by teachers and engineering college student;

- Study the purpose and frequency of using the electronic resources and services available in the library;

- Locate the impediments faced by the teachers and students while accessing and using the electronic resources in the library;

- Study the impact of electronic recourses and services on the academic work of the teachers and engineering student;

- Know the productivity and quality of information retrieved through e- resources.

\section{Previous studies}

A number of relevant studies have been carried out on the use of e- resources by teachers, and engineering student of campus organizations. Seventy-eight percent of the respondents feel that the use of the UGC- info net e- journals has created high dependency value on their research work and they needed current article alert services and electronic document supply services (Madhusudhan 2008). 267.64\% of Student of faculty of Physics and 69.23\% of student of engineering use of e- journals for research work whereas $35.29 \%$ of sciences use e- journals to update Knowledge and $23.70 \%$ of engineering use these for study. 3 Speed of available and the ease of accessibility of information Causes the users to use electronic resources more frequently. $\underline{4} 49 \%$ of respondents are marginally satisfied with online services provided by the library. The survey indicated that the use of e- resources in jamia Islam is not satisfactory and needs constant guideline ?orientation to enhance their usage. $\underline{5} \mathrm{E}$ - journals are becoming a basic need for the academic student everyday Navjyoti finds that speedy publication and availability on the desktop are the key advantages that attract research scholars. 
6 Lack of training is a major de- motivating Factor in the usage of e- journals, so that needs to be improved . Kennedy proposes the inclusion of Web pages to the library Catalogue as a solution to the maintenance of increasing web site links. 7 Kaur report E- Resources Can be good Substitutes for conventional resources if the access speed is fast, access to all the important E- journals is provided and more computer terminals are installed to provide access to e- resources. $\underline{8}$ Renwick recommends there be greater promotion of the library's E - resources. 9 Kaur and verma find that users use all the sources available to them regularly, like CD ROMs, online databases, Web Resources and audio/ video Tapes.10

\section{Survey Design}

The study was limited to the teacher and engineering college student of siddhivinayak technical campus, khamgaon, India.

A questionnaire survey was conducted to collect the information regarding the use of the e- resources, Frequency of use of e- resources, purpose of using e- resources ,frequency of locating desired information, problems faced by users while using e- resources . total of 100 questionnaires were found usable for analysis . the Questionnaires were completed by personal visits with users. Questionnaires were distributed randomly to the users. The collected data was analyzed and presented in the tabular form.

\section{Discussion}

Table 1. Use of Various E- Resources

\begin{tabular}{|l|l|l|}
\hline \multirow{2}{*}{ Databases } & Respondents \\
\cline { 2 - 3 } & Student & Teachers \\
\hline E-journals & $46(88.46 \%)$ & $28(93.33 \%)$ \\
\hline E- Maps & $04(07.69 \%)$ & $04(13.33 \%)$ \\
\hline E- Books & $16(30.77 \%)$ & $05(16.66 \%)$ \\
\hline E-Magazines & $14(26.92 \%)$ & $19(63.33 \%)$ \\
\hline E- Thesis & $05(09.61 \%)$ & $03(10.00 \%)$ \\
\hline WWW & $30(57.69 \%)$ & $23(76.66 \%)$ \\
\hline E- Newspaper & $14(26.92 \%)$ & $03(10.00 \%)$ \\
\hline E- Mail & $41(78.84 \%)$ & $18(60.00 \%)$ \\
\hline E- Research Reports & $16(30.77 \%)$ & $15(50.00 \%)$ \\
\hline E- Bibliographic Databases & $10(19.23 \%)$ & $03(10.00 \%)$ \\
\hline
\end{tabular}

Table 1 show that the majority of the student $46(88.46 \%)$ and teachers $28(93.33 \%)$ prefer to usejournals. Second highest preference is WWW and use of e- mail with 30(57..69\%) and among students whereas $23(76.66 \%)$ and $18(60.00 \%)$ among Teachers. 50\% of teachers and $30.77 \%$ of students make the use of eresearch reports. Table 1 highlights that only the well- known e- resources are preferably used by the researches and student, the rest of the well-known e- resources are preferably used by the research and student, the rest of the e- resources I.e. E-bibliography, e- maps, e-thesis, e-books are comparatively less used.

Table 2. Ease of Access to E- Resources

\begin{tabular}{|l|l|l|l|}
\hline Respondents & Total & Yes & No \\
\hline Students & 52 & $42(80.70 \%)$ & $10(19.23 \%)$ \\
\hline Teachers & 30 & $26(86.67 \%)$ & $04(13.33 \%)$ \\
\hline
\end{tabular}

Table 2 represents that $42(80.77 \%)$ Students and $26(86.67 \%)$ Teachers are able to access the eresources very easily. Only $10(19.23 \%)$ Students and $4(13.33 \%)$ teachers feel that to use the e- resources is not easy. Although Siddhivinayak technical campus, there is still a need to train faculty members and student in the use of e- resources.

Table3. User - friendly interface to the library Website

\begin{tabular}{|l|l|l|l|}
\hline RESPONDENTS & TOTAL & YES & NO \\
\hline Student & 52 & $43(82.69 \%)$ & $9(17.31 \%)$ \\
\hline Teacher & 30 & $24(80.00 \%)$ & $6(20.00 \%)$ \\
\hline
\end{tabular}

Table 3 highlights that majority of Student, i.e. 34(65.38\%), and Teacher, i.e. 24(80.00\%), respond that the interface of the library Web site is user - friendly. Few of Students , I.e. 9 (17.31\%), or Faculty members i.e. 6 (20.00\%), think that the interface of the library web site is not user - friendly. 
Table 4. Use of the Web site as a Gateway to Access Electronic Resource

\begin{tabular}{|l|l|l|l|}
\hline Respondents & Total & yes & No \\
\hline student & 52 & $34(65.38 \%)$ & $18(34.61 \%)$ \\
\hline Teachers & 30 & $23(76.67 \%)$ & $7(23.33 \%)$ \\
\hline
\end{tabular}

Table 4 show that the majority of Students, i.e. $34(65.38 \%)$, and teacher, i.e. $23(76.67 \%)$ are using the library Web site as Gateway to access the electronic sources. A few of the students, i.e. 18 (34.61\%), and Teachers i.e. 7 ( $23.33 \%$ ), are not using the library Web site as gateway to access the electronic sources.

Table 5. Training Taken

\begin{tabular}{|l|l|l|l|}
\hline Respondents & Total & yes & No \\
\hline Student & 52 & $27(51.92 \%)$ & $25(48.08 \%)$ \\
\hline Teacher & 30 & $18(60.00 \%)$ & $12(40.00 \%)$ \\
\hline
\end{tabular}

\section{Related to Electronic resources}

Table 5 shows that $27(51.92 \%)$ Students have taken the training regarding the access to electronic resources, while $25(48.08 \%)$ Students didn't get any training regarding the access to electronic resources. A majority of Faculty members i.e. 27 (90.00\%), didn't get training in the use of electronic resources and few of the teachers, i.e. $3(10.00 \%)$ got training in the access of electronic resources

Table - 6 Frequency of using E- resources

\begin{tabular}{|l|l|l|l|l|}
\hline Respondents & Total & usually & Sometimes & Rarely \\
\hline Students & 52 & $33(63.46 \%)$ & $15(28.85 \%)$ & $4(7.69 \%)$ \\
\hline Teacher & 30 & $26(86.67 \%)$ & $4(13.33 \%)$ & - \\
\hline & & & & \\
\hline
\end{tabular}

Table -6 Reveals that $33(63.46 \% 0$ Students and 26 ( 86.67\%) research scholars usually use e- resources. 15 ( $28.85 \%)$ students and $4(13.33 \%)$ teacher use the e- resources some times, whereas 4 ( $7.69 \% 0$ students use eresources rarely. It is noted that teacher use the library e- resources more frequently than the students.

Table-7. Where do you mostly access required information

\begin{tabular}{|l|l|l|}
\hline E- Resources & students & Teacher \\
\hline E- Books & $5(9.62 \%)$ & $2(6.67 \%)$ \\
\hline E- journals & $24(46.15 \%)$ & $17(56.67 \%)$ \\
\hline Online- Databases & $9(17.13 \%)$ & $9(30.00 \%)$ \\
\hline Search Engines & $37(71.15 \%)$ & $14(46.67 \%)$ \\
\hline
\end{tabular}

Table -7 reveals that most respondents access e- journals and such engines to get required information at stc. 24(46.15\%) Student and 17(56.67\%) Teachers prefer to use e- journals whereas 37 (71.15\%) Student and $14(46.67 \%)$ teacher make the use of search engines to get the desired material. Online databases are also very popular among the students and Teachers, as $9(30.00 \%)$ of them prefer to use these. Use of e- books is used less by the students scholars access the maximum relevant material from e- journals.

Table 8. Searching Other Libraries' Catalogues.

\begin{tabular}{|l|l|l|l|}
\hline Respondents & Total & Yes & No \\
\hline Student & 52 & $20(38.40 \%)$ & $32(61.54 \%)$ \\
\hline Teachers & 30 & $18(60.00 \%)$ & $12(40.00 \%)$ \\
\hline
\end{tabular}

Table 8. Highlights the fact that $20(38.46 \%)$ Students and $18(60 \%)$ research teachers search the catalogues of other libraries. 32 (61.54) Students and 12 (40.00\%) Teachers do not retrieve catalogues of other libraries. The majority of the Students is not interested in the catalogues of the other libraries, this indicates that STC library fulfills their requirements

Table 9. Use of PowerPoint Presentations in Teaching.

\begin{tabular}{|l|l|l|l|}
\hline Respondents & Total & Yes & No \\
\hline Students & 52 & $37(71.15 \%)$ & $15(28.85 \%)$ \\
\hline Teacher & 30 & $26(86.67 \%)$ & $413.33 \%)$ \\
\hline
\end{tabular}

Table 9. Reveals that $37(71.15 \%)$ Students and $26(86.67 \%)$ research Teacher make the use of PowerPoint in their class teaching. Only 15 (28.85\%) teachers and 4 (13.33\%) researchers do not prefer PowerPoint presentation for teaching the classes. 
Table 10. Frequency of Use of Different Databases.

\begin{tabular}{|c|c|c|c|c|c|c|c|c|}
\hline \multirow[t]{2}{*}{ Databases } & \multicolumn{2}{|l|}{ Use Often } & \multicolumn{2}{|c|}{ Use Sometimes } & \multicolumn{2}{|l|}{ Never Use } & \multicolumn{2}{|c|}{ Unfamiliar With } \\
\hline & Student & Teachers & Students & Teachers & Students & Teachers & Students & Teachers \\
\hline IEEE & $8(15.38 \%)$ & $8(26.66 \%)$ & $9(17.30 \%)$ & $5(16.66 \%)$ & $15(28.84 \%)$ & $6(20 \%)$ & $9(17.30 \%)$ & $2(6.66 \%)$ \\
\hline Nature & $6(11.53 \%)$ & $2(6.66 \%)$ & $12(23.07 \%)$ & $6(20 \%)$ & $16(30.76 \%)$ & $4(13.33 \%)$ & $9(17.30 \%)$ & $4(13.33 \%)$ \\
\hline Emerald & $5(9.61 \%)$ & $4(13.33 \%)$ & $14(26.92 \%)$ & $5(16.66 \%)$ & $9(17.30 \%)$ & $6(20 \%)$ & $6(11.53 \%$ & $4(13.33 \%)$ \\
\hline $\begin{array}{ll}\text { Web } & \text { of } \\
\text { Science } & \\
\end{array}$ & $5(9.61 \%)$ & $4(13.33 \%)$ & $13(25 \%)$ & $8(26.66 \%)$ & $7(13.46 \%)$ & $8(26.66 \%)$ & $7(13.46 \%)$ & $4(13.33 \%)$ \\
\hline $\begin{array}{l}\text { Science } \\
\text { Direct }\end{array}$ & $24(46.15 \%)$ & $18(60 \%)$ & $8(15.38 \%)$ & $4(13.33 \%)$ & $10(19023 \%)$ & $2(6.66 \%)$ & $6(11.53 \% 0$ & $2(6.66 \%)$ \\
\hline ACM & $6(11.53 \%)$ & $3(10 \%)$ & $7(13.46 \%)$ & --- & $15(28.84 \%)$ & $9(30 \%)$ & $10(19.23 \%)$ & $6(20 \%)$ \\
\hline Wikipedia & $18(36.61 \%)$ & $8(26.66 \%)$ & $16(30.76 \%)$ & $6(20 \%)$ & $4(7.69 \%)$ & $5(16.66 \%)$ & $1(1.92 \%)$ & $2(6.66 \%)$ \\
\hline $\begin{array}{l}\text { Springer } \\
\text { Link }\end{array}$ & $20(38.46 \%)$ & $16(53.33 \%)$ & $9(17.30 \%)$ & $7(23.33 \%)$ & $7(13.46 \%)$ & $2(6.66 \%)$ & $6(11.53 \%)$ & $2(6.66 \%)$ \\
\hline $\begin{array}{l}\text { UGC Info } \\
\text { Net }\end{array}$ & $5(9.61 \%)$ & --- & $21(40.38 \%)$ & $8(26.66 \%)$ & $7(13.46 \%)$ & $7(23.33 \%)$ & $5(9.61 \%)$ & $5(16.66 \%)$ \\
\hline
\end{tabular}

Table 10. Shows that majority of the Students use Science Direct, Springer Link and Wikipedia often, i.e.24 (46.51\%). 20(38061\%) and 18(34.61\%) respectively, whereas 18(60\%) Teachers use Science Direct often and $16(53.33 \%)$ use Springer Link often. Use of IEEE is not frequent among respondents; it may be due to access being restricted to five users at STC. 12(23.07\%) Students and 6(20\%) Teachers sometimes use sometimes. 21(40.38\%) Students and 8(26.66\%) Teachers use UGC Info Net sometimes whereas $20 \%$ of respondents are unfamiliar with STC which is shocking in a technical Campus.

Table 11. Reasons for Using E-Resources.

\begin{tabular}{|l|l|l|}
\hline Reasons for Using E-Resources & Students & Teachers \\
\hline Time Saving & $39(75.00 \%)$ & $18(60.00 \%)$ \\
\hline Time Consuming & $3(5.77 \%)$ & --- \\
\hline Easy to Use & $34(65.38 \%)$ & $24(80.00 \%)$ \\
\hline Difficult to Use & $4(7.79 \%)$ & --- \\
\hline More Informative & $25(48.08 \%)$ & $18(60.00 \%)$ \\
\hline Less Informative & $3(5.77 \%)$ & --- \\
\hline More Expensive & $5(9.62 \%)$ & $6(20.00 \%)$ \\
\hline Less Expensive & $6(11.54 \%)$ & $12(40.00 \%)$ \\
\hline More Useful & $27(51.92 \%)$ & $18(60.00 \%)$ \\
\hline Less Useful & $3(5.77 \%)$ & --- \\
\hline
\end{tabular}

Table 11. Elaborates that majority of the Students prefer to use e-resources in comparison to traditional resources because $39(75 \%)$ of them feel that e-resources are time saving, followed by easy to use, i.e. $34(65.38 \%)$, further followed by more useful and more informative, i.e.27(51.92\%) and 25(48.08\%) respectively. $60 \%$ of Students prefer to use e-resources because they feel that e-resources due to their easiness. $6(11.54 \%)$ Student and $12(40.00 \%)$ researchers are less useful. The results from table 11 reveal that eresources are much preferred by respondents due to their nature of being more informative, more useful, and less expensive.

Table 12. Satisfaction with Existing IT Infrastructure.

\begin{tabular}{|l|l|l|l|}
\hline Respondents & Total & Yes & No \\
\hline Students & 52 & $21(40.38 \%)$ & $31(59.52 \%)$ \\
\hline Teachers & 30 & $13(43.33 \%)$ & $17(56.67 \%)$ \\
\hline
\end{tabular}

Table 12. Shows that the majority of Students, 31(59.62\%), and teachers, 17 (56.67\%), are not satisfied with the existing IT infrastructure within the organization. Only 21(40.38\%) Students and 13(43.33\%) Teachers are satisfied with the IT infrastructure of the Campus. Results shows that being an engineering Campus, STC does not have sound IT infrastructure facilities.

Table 13. Do E-Resources Diminish the Importance of Traditional Resources.

\begin{tabular}{|l|l|l|l|}
\hline Respondent & Total & Yes & No \\
\hline Students & 52 & $20(38.46 \%)$ & $32(61.54 \%)$ \\
\hline Teachers & 30 & $8(26.67 \%)$ & $22(73.33 \%)$ \\
\hline
\end{tabular}


Table 13. Reveals that a huge amount of Students, 32(61.54\%), and Teachers, 22(73.33\%) think that eresources never diminish the light of traditional resources, whereas $20(38.46 \%)$ Students and 8(26.67\%) Teachers feel that e-resources may replace traditional sources of information. The results of table 13 shows that in the era of information and technology, academics are equally attached to traditional sources of information.

\section{Conclusion}

Study shows the use of e- resources is very common among the teachers and students of Siddhivinayak technical campus and majority of the teachers and student are depend on e-resources to get the desired and relevant information. But practical use of e- resources is not up to the worth in comparison to investments made in revised as per requirements . it is observed that the availability of e- resources on the campus is almost sufficient for all the existing disciplines but the infrastructure to use these resources is not adequate and can the ability to meet the requirements of users .

\section{Acknowledgements}

The researcher is thankful to the principal SiddhiVinayak Technical Campus ex Dr. Kishor P. Kolhe sir, for releasing sufficient material, \& Guideline for this study. The author is thankful to Chairman Siddhivinayak technical campus Mr. Sager P. Fundker for available the campus research facility for conducting the research experiments of this study.

\section{References}

[1]. Madhusudan M, "use of UGC infonet e- journals by research scholars of university of Delhi,Delhi”, Library Hi Tech, Vol.26 No.3. pp. 369-386.

[2]. Narayana poornima and Goudar IRN, “E- Resources Management ( ICIM2005), 22-25 Feb2005, P 1-19.

[3]. Kaur Amritpal, use of E- resources by teachers and researches of the Science and Engineering \& Technology Faculties in guru Nanak Dev University: A Survey .in NACLIN 2006, p267-285.

[4]. RenWick Shamin,Knoweledge and use electronic Resources by medical Science Faculty at the university of the West indies. Libri, Vol.43, No.3, 2004, p58-64.

[5]. Kaur Baljinder \& verma Rama, use of electronic resoueces at TIET Library Patiala: A Case Study. ILA Bulletin, Vol.42, no.3, 2006,p 18-20.

[6]. Eqbal Monawwer \& Khan Azhar Shah, use of Electronic journals by research Scholars of Faculty of Science and Faculty Of Engineering, In: NACLIN2007, P309-319.

[7]. Chetan Sharma, Use and impact of E- Resources at Guru Gobind Singh Indraprastha university (india): A Case study.Vol.10 No.1,2009.

[8]. Naqvi shehbaz Husain, Use of electronic Resources at Jamia Millia (A Central university): A case Study, In: NACLIN 2007, p320324.

[9]. Navijyoti, A snapshot of E- journals' Adopters (Research Scholars) of Guru Nanak Dev university, In: NACLIN 2007,p432-442.

[10]. Kennedy,P (2004), "Dynamic Web Pages and the library Catalogue”, The Electronic library, Vol.22 No. 6. Pp.480-6. 